\title{
BENIGN ANASTOMOTIC STRICTURES AFTER TRANSHIATAL ESOPHAGECTOMY AND CERVICAL ESOPHAGOGASTROSTOMY: RISK FACTORS AND MANAGEMENT
}

\author{
P. Honkoop, MD \\ P. D. Siersema, MD, $\mathrm{PhD}^{\mathrm{a}}$ \\ H. W. Tilanus, MD, $\mathrm{PhD}^{\mathrm{b}}$ \\ L. P. S. Stassen, MD, PhD ${ }^{b}$ \\ W. C. J. Hop, $\mathrm{MSc}^{\mathrm{c}}$ \\ M. van Blankenstein, $\mathrm{MD}^{\mathrm{a}}$
}

\begin{abstract}
Benign stricture formation at the cervical anastomosis after transhiatal esophagectomy with gastric tube interposition is an important source of morbidity. In a large group of patients $(n=269)$ who had undergone transhiatal esophagectomy with gastric tube interposition, we examined surgical and nonsurgical risk factors for the development of benign strictures at the cervical anastomosis. In addition, we evaluated the results of endoscopic bougie dilation in patients in whom an anastomotic stricture developed. Results: During follow-up, 114 patients $(42 \%)$ had a benign anastomotic stricture. Only a history of cardiac disease $(p=0.03)$, postoperative leakage at the anastomosis $(p=0.002)$, and a stapled rather than a hand-sewn anastomosis $(p=0.04)$ were found to be independent risk factors for the development of a stricture. In 27 of 60 patients with anastomotic leakage, contrast swallow examination demonstrated only a leak at the anastomosis. Endoscopic bougie dilation of anastomotic strictures was successful in $78 \%$ of patients after a median of three dilation sessions (range 1 to 28 ). In $3 \%$ of patients dilations were still being performed, and $19 \%$ of patients had died before normal swallowing had been achieved. In two of $519(0.4 \%)$ dilation sessions a major complication occurred. Conclusions: (1) Patients with preoperative cardiac disease are at an increased risk for anastomotic stricture. (2) Even in patients having no symptoms, a contrast swallow can detect anastomotic leakage that results in an increased risk for the development of anastomotic strictures. (3) The benefit of the stapler device for anastomosis remains to be determined. (4) Endoscopic bougie dilation with the patient mildly sedated is a safe and effective method for the treatment of anastomotic strictures. ( $J$ Thorac Cardiovasc Surg 1996;111:1141-8)
\end{abstract}

$E^{s}$ sophageal resection for carcinoma of the esophagus or gastric cardia with immediate reconstruction is considered the standard surgical treatment in

From the Department of Internal Medicine II, aDivision of Gastroenterology, and the Department of Surgery, ${ }^{b}$ University Hospital Rotterdam-Dijkzigt, and the Department of Epidemiology and Statistics, 'Erasmus University Rotterdam, Rotterdam, The Netherlands.

Presented in part at the meeting of the American Gastroenterological Association during the Digestive Disease Week, San Diego, Calif., May 1995.

Received for publication July 11, 1995; accepted for publication Oct. 5, 1995.

Address for reprints: P. Honkoop, MD, Department of Internal Medicine II, Division of Gastroenterology (Room Ca 405), University Hospital Rotterdam-Dijkzigt, Dr. Molewaterplein 40, 3015 GD Rotterdam, The Netherlands.

Copyright (C) 1996 by Mosby-Year Book, Inc.

$0022-5223 / 96 \$ 5.00+0 \quad \mathbf{1 2 / 1 / 6 9 7 4 7}$ the absence of distant metastasis. After transhiatal esophagectomy, swallowing can be restored by gastric tube interposition with the anastomosis made in the neck or in the chest. ${ }^{1-3}$ However, the development of benign strictures at the cervical anastomosis is a major source of morbidity. The frequency of this problem ranges from $5 \%$ to $46 \%$ in the more recent literature. ${ }^{3-13}$ Factors responsible for anastomotic stricture formation have been poorly defined. ${ }^{14}$ In two studies with the purpose of identifying factors responsible for anastomotic stricture formation, preceding anastomotic leakage, ${ }^{10,11}$ intraoperative blood loss, ${ }^{10}$ and poor vascularization of the gastric tube (judged perioperatively) ${ }^{11}$ were found to be independent risk factors for stricture formation.

Benign anastomotic strictures after esophagogastrostomy are usually treated with an endoscope. However, in various studies, $8,10,11,15-18$ the range in the number of dilation sessions (between 2 and 9.5 
Table I. Risk factors analyzed for the development of benign strictures at the cervical esophagogastrostomy

Preoperative factors
Age, sex, previous medical history (cardiac, pulmonary, dia-
betes mellitus), medication (cardiac, pulmonary, other), car-
diac function (electrocardiogram), pulmonary function
(forced expiratory volume in 1 second, Tiffenau-index,
arterial blood gases), endoscopic localization of tumor
(esophagus or cardia), chemotherapy or radiotherapy
Intraoperative factors
Length of operation, placement of gastric tube (anterior or
posterior mediastinum), surgical method of reconstruction
(end-to-end or end-to-side), surgical technique of reconstruc-
tion (hand sewn or stapler device), intraoperative blood loss
(number of transfusions), total number of Astrups
Postoperative factors
Surgical complications (rebleeding, chylothorax, paralytic re-
currence nerve, wound infection), nonsurgical complications
(pneumonia, adult respiratory distress syndrome, myocardial
infarction, sepsis), anastomotic leakage, tumor histologic type
(squamous cell or adenocarcinoma), tumor stage (TNM clas-
sification), tumor grade of differentiation, chemotherapy or
radiotherapy

sessions) needed to alleviate dysphagia varied widely.

The aim of this study was to determine both surgical and nonsurgical risk factors for the development of benign strictures at the cervical anastomosis in a large group of patients $(n=269)$ after transhiatal esophagectomy with gastric tube interposition. In addition, we have evaluated the results of endoscopic dilation treatment in patients in whom anastomotic strictures developed after cervical esophagogastrostomy.

\section{Patients and methods}

From January 1987 to July 1993, 319 patients underwent resection for carcinoma of the esophagus or esophagogastric junction. Patients with a colonic interposition $(n=24)$, a laryngopharyngectomy $(n=6)$, or a transthoracic esophagectomy $(n=8)$ were excluded. There remained 281 patients undergoing a transhiatal esophagectomy with gastric tube reconstruction and cervical anastomosis. In six of these patients a major dehiscence developed at the esophagogastric anastomosis, necessitating takedown of the anastomosis within 10 days after the operation. Of the remaining 275 patients, six died in the postoperative period ( $<30$ days). Finally, 269 patients were included in the study who were at risk for development of a benign cervical anastomotic stricture. In all patients, a $3 \mathrm{~cm}$ wide gastric tube was created along the greater curvature with a linear stapler (Auto Suture Company Division, United States Surgical Corporation, Norwalk, Conn.). In 114 of 269 (42\%) patients the cervical anastomosis between the remaining esophagus and the gastric tube was performed manually with a one-layer continuous suture of 3-0 polydioxanone (Ethicon, Norder- stedt, Germany), and in 154 of $269(57 \%)$ patients the cervical anastomosis was constructed with 21 or $25 \mathrm{~mm}$ mechanical circular stapler devices (EEA, Auto Suture; or ILS, Ethicon). All but three patients underwent a radiographic swallow examination with water-soluble contrast medium between the seventh and tenth postoperative days to detect anastomotic leakage. In the preoperative period, chemotherapy was administered to 31 patients and radiotherapy to 24 . In the postoperative period ( $<6$ weeks after operation), chemotherapy was administered to 31 patients and radiotherapy to one patient. Median follow-up time of the patients was 15 months and ranged from 4 weeks to 83 months. In patients not dying of tumor recurrence or of diseases unrelated to the original tumor, follow-up time was at least 6 months.

The potential risk factors analyzed as being of a priori influence on the prevalence of anastomotic strictures are summarized in Table I. Most data were available from a prospectively collected database on patients with carcinoma of the esophagus or esophagogastric junction. Other factors were collected retrospectively from the records.

Patients were routinely seen in the outpatient clinic at 6 weeks and 3 months, subsequently at 3-month intervals for 1 year, and at 6 -month intervals after 1 year. At every visit, the esophagus was assessed for the quality of swallowing (grade 1, normal swallowing; grade 2, dysphagia for solids; grade 3, dysphagia for semisolids; grade 4, dysphagia for liquids. When patients had dysphagia of grade 2 or worse, an endoscopic assessment was performed. If indicated, biopsy specimens of anastomotic strictures were obtained to rule out tumor recurrence. Strictures were treated endoscopically with bougie dilation, as described by Savary, Haury, and Monnier, ${ }^{19}$ using Celestin dilators (Medoc, Tetbury, United Kingdom) or a Keymed advanced dilator (Keymed, Southend-on-Sea, United Kingdom). In all patients, endoscopic dilation to $18 \mathrm{~mm}$ was performed. Mild sedation with midazolam (Dormicum, Roche Nederland BV, Mijdrecht, The Netherlands) was used in all cases. Dilation was continued until the patient was able to eat solids (with or without liquids with meals) or until death. The cumulative incidence of anastomotic stricture was estimated by life-table methods. ${ }^{20}$ The influence of potential risk factors (see Table I) on the occurrence of anastomotic strictures was univariately evaluated by the $\log$ rank test. Cox regression ${ }^{21}$ was used to evaluate various factors simultaneously regarding the risk of stricture development. Statistical significance was defined as $p \leq 0.05$.

\section{Results}

Sixty-eight women and 201 men were included in this study, with a mean ( \pm standard deviation) age of $61 \pm 9.9$ years (ranging from 35 to 82 years). The tumor was localized in the proximal third of the intrathoracic esophagus in three patients, in the middle third in 54 patients, in the distal third in 103 patients, and at the esophagogastric junction in 109 patients. Histologic examination showed a squa- 


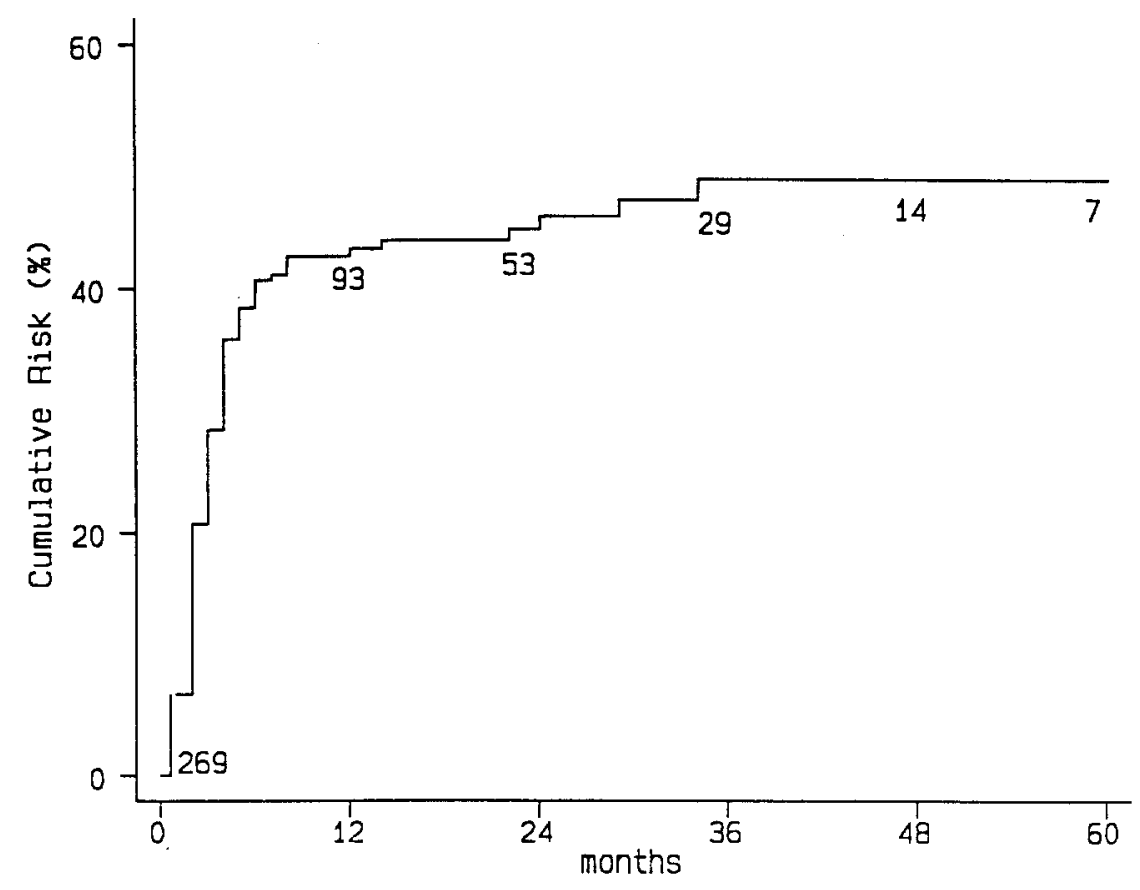

Fig. 1. The estimated risk of a stricture developing at the esophagogastric anastomosis. The patients at risk for development of a stricture, at subsequent years after the operation, are given.

mous cell carcinoma in 92 patients and an adenocarcinoma in 161 patients; 55 of the latter patients had an adenocarcinoma in Barrett's epithelium. In 11 patients an undifferentiated carcinoma was found, and in five patients the carcinoma was designated "other."

In 114 of 269 patients (42\%), a benign anastomtic stricture developed between 4 and 149 (median 11) weeks after operation. The estimated risk of a stricture developing at the esophagogastric anastomosis was $43 \%$ within 1 year. After this period the risk of a stricture developing increased to $46 \%$ within 2 years and $49 \%$ within 3 years (Fig. 1). All anastomotic strictures were confirmed with an endoscope. Table II shows the statistically significant risk factors for development of a benign stricture at the cervical esophagogastrostomy. Of the preoperative factors, only a history of cardiac disease was a risk factor for development of an anastomotic stricture $(p=0.03)$. Postoperative leakage at the anastomosis also entailed an increased risk of stricture development $(p=0.002)$. Remarkably, 27 of 60 patients with only radiologic signs of leakage, but without clinical symptoms, were at an increased risk of stricture development. No difference was detected between clinically evident and radiologic anastomotic leakage in the incidence of stricture
Table II. Risk factors for development of benign stricture at cervical esophagogastrostomy (leakage at the cervical esophagogastrostomy as demonstrated by clinical symptoms and radiographic swallow examination or by radiographic swallow examination only)

\begin{tabular}{lrrr}
\hline & \multicolumn{2}{c}{ Stricture } & \\
\cline { 2 - 3 } & $\begin{array}{c}\text { Yes } \\
(n=114)\end{array}$ & $\begin{array}{c}\text { No } \\
\end{array}$ & \\
& $(n=155)$ & $p$ Value \\
\hline $\begin{array}{l}\text { Preoperative cardiac disease } \\
\text { Yes (20\%) }\end{array}$ & $28(53 \%)$ & $24(47 \%)$ & 0.03 \\
$\quad$ No (80\%) & $86(40 \%)$ & $128(60 \%)$ & \\
Anastomotic technique & & & \\
$\quad \begin{array}{l}\text { Hand sewn (43\%) } \\
\text { Stapler (57\%) }\end{array}$ & $40(35 \%)$ & $75(65 \%)$ & 0.04 \\
Postoperative leakage & $74(48 \%)$ & $80(52 \%)$ & \\
$\quad$ Yes (23\%) & $34(57 \%)$ & $26(43 \%)$ & 0.002 \\
$\quad$ No (77\%) & $79(38 \%)$ & $127(62 \%)$ & \\
If postoperative leakage & & & \\
$\quad(n=60):$ & $16(48 \%)$ & $17(52 \%)$ & 0.2 \\
Clinical + radiologic: & & & \\
$\quad 33(13 \%)$ & $18(67 \%)$ & $9(33 \%)$ & \\
$\quad$ Radiologic alone: $27(10 \%)$ & & & \\
\hline
\end{tabular}

formation $(p=0.38)$. Of the perioperative factors, the surgical technique used for constructing the anastomosis was a third risk factor (Fig. 2). Strictures developed more often in patients with a stapled anastomosis than in patients with a hand-sewn 


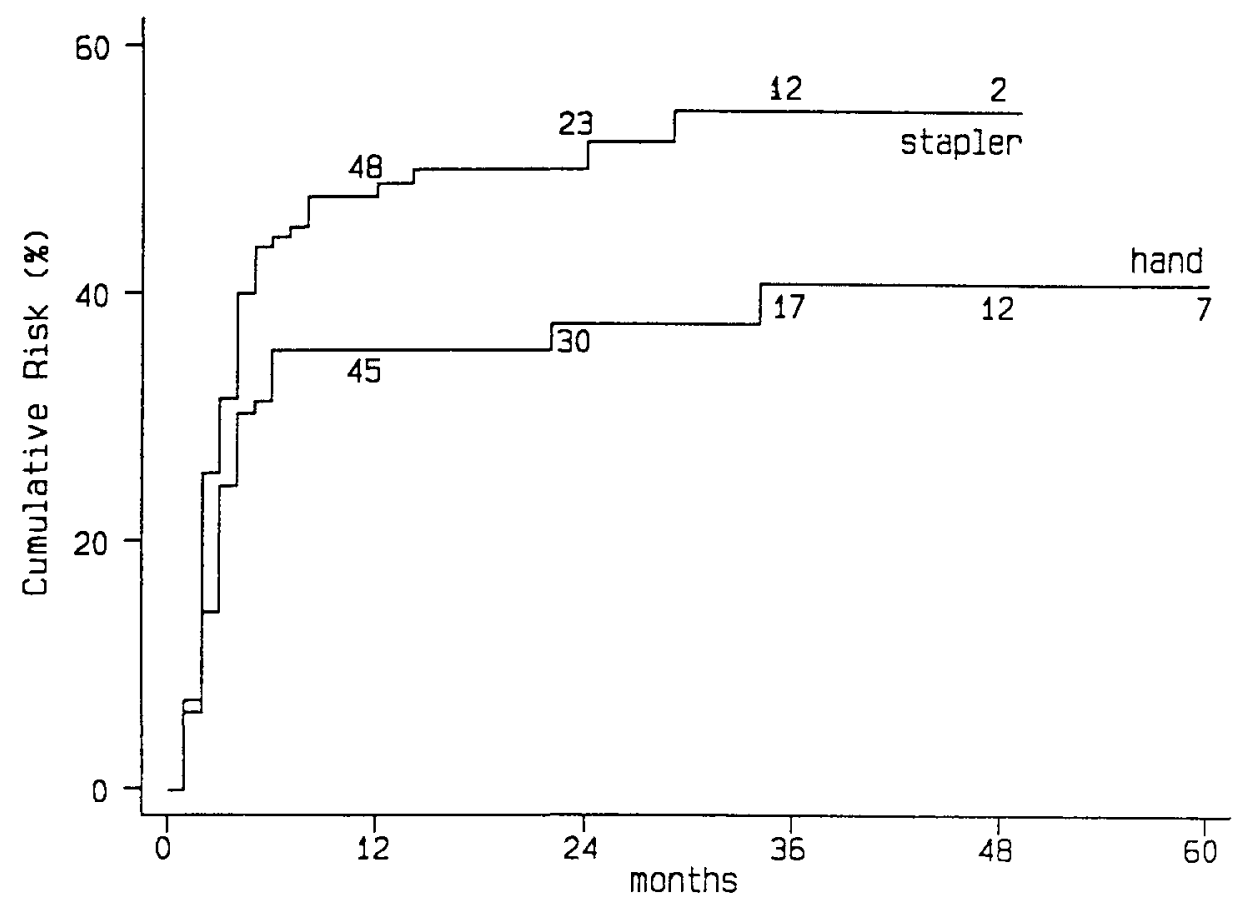

Fig. 2. The surgical technique used for construction the anastomosis (stapled versus hand-sewn) as a risk factor for the development of a stricture at the esophagogastric anastomosis.

anastomosis $(p=0.04)$. These three risk factors were independently related to the occurrence of strictures as shown by multivariate analysis.

The 114 patients with a benign anastomotic stricture underwent a total of 519 dilation sessions, with a median of three sessions (ranging from one to 28) per patient. Dilation achieved normal swallowing in $89(78 \%)$ patients. In three $(3 \%)$ patients dilations were still being performed at the end of the study period, and $22(19 \%)$ patients had died of recurrent illness or disease unrelated to the original tumor before normal swallowing had been achieved (Fig. 3). After five of 519 (1\%) dilation sessions, one night's observation in the hospital was thought necessary because of suspicion of perforation. In two patients perforation had in fact occurred at the anastomotic site, one resulting in the development of mediastinitis and the other in major bleeding. These two patients died of these complications.

\section{Discussion}

Transhiatal esophagectomy performed through an abdominal and cervical incision is one of the standard procedures in the surgical treatment of patients with carcinoma of the esophagus or gastric cardia. ${ }^{2,22}$ However, the outlook of surgical treatment is bleak because most patients are beyond curative surgical therapy when they initially seek treatment. The subsequent development of a benign anastomotic stricture nullifies the relief of dysphagia, which is the main object in patients with a short life expectancy. ${ }^{1}$ The incidence of benign anastomotic strictures ranges from $5 \%$ to $46 \%$ in the more recent literature. ${ }^{3-13}$ In our study, the incidence of strictures after cervical esophagogastrostomy was $42 \%$ at 1 year after operation. This high rate of stricture formation can be explained, at least in part, by the fact that in most series the incidence may be underestimated: often all patients undergoing esophagogastrostomy, and not just those actually surviving, are included in the denominator. ${ }^{23}$ In addition, the wide range of reported incidences might also be due to the variable definition of a stricture. In this study, an anastomotic stricture was defined as being present with any degree of dysphagia. Apart from this, we found in our study three additional risk factors for development of an anastomotic stricture.

1. Of the preoperative factors, only a history of cardiac disease, for example, angina, myocardial infarction, or cardiac failure, was a risk factor for anastomotic stricture (see Table II). Ischemia of the upper part of the gastric tube is considered to be the most important cause in the development of anas- 


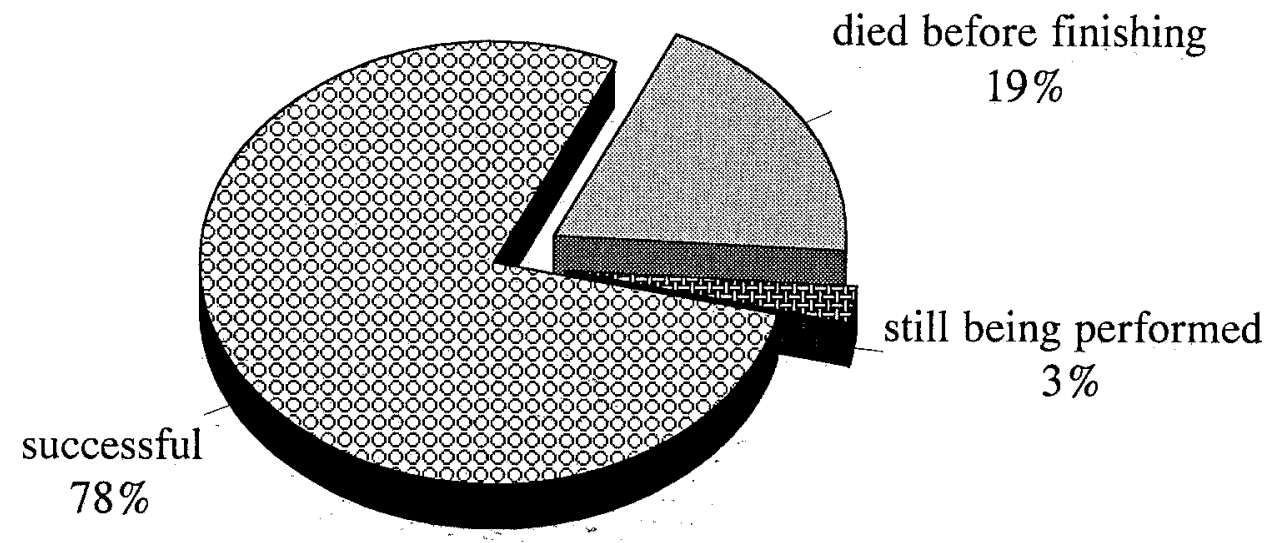

Fig. 3. Results of endoscopic bougie dilatation in 114 patients with stricture formation at esophagogastrostomy.

tomotic strictures. ${ }^{3,11}$ When the gastric tube is being constructed to reach the neck, only the right gastroepiploic artery remains intact. Moreover, the oral part of the gastric tube depends solely on intramural blood supply. ${ }^{24,25}$ In an experimental model, Aiko and associates ${ }^{26}$ demonstrated an accumulation of neutrophils and a subsequent increase in the oxygen radical-generating ability in the low-flow hypoxic upper part of the gastric tube in dogs. Therefore it seems likely that in patients with a history of cardiac disease, anastomotic strictures may be caused by (temporary) changes in circulation resulting from cardiac failure, producing ischemia in a gastric tube whose perfusion is already critically impaired. The significance of this observation is that meticulous surgical technique should be used when an anastomosis is being created between the remaining esophagus and the gastric tube.

2. Of the postoperative factors, leakage at the esophagogastric anastomosis, as in other studies, $8,10,11$ was a risk factor for the development of strictures. The incidence of $23 \%$ is within the reported range from $0 \%$ to $53 \% .^{3-14,27,28}$ We found that the incidence of leakage was $28 \%$ in hand-sewn and $19 \%$ in stapled anastomoses $(p=$ not significant; results not shown). These figures are in accordance with other reports. ${ }^{14}$ Leakage was clinically evident in 33 patients but was found only by radiographic examination in the other 27 patients (see Table II). In our opinion, a postoperative radiographic check is useful not only for identifying patients at risk for development of an anastomotic stricture, but also to discover asymptomatic leaks so that patients can be prevented from swallowing before the leak has healed. ${ }^{14}$
3. The only perioperative risk factor found to influence the development of anastomotic strictures was the anastomotic technique. The stricture rate was significantly higher in patients with a stapled as compared with a hand-sewn anastomosis (see Fig. 2). Stapled anastomoses have been recognized as a risk factor favoring the development of anastomotic strictures., 4, 6, 7,9 Moreover, strictures are significantly more prevalent when smaller staplers are used. ${ }^{3,6}$ In this study, $21 \mathrm{~mm}$ or $25 \mathrm{~mm}$ stapler devices were used. Fok and Wong ${ }^{3}$ recently reported a relative risk of $46 \%$ when small $(25 \mathrm{~mm})$ staplers were used, as compared with a risk of $14 \%$ with large (31 and $33 \mathrm{~mm}$ ) staplers. The differences in stricture rates between hand-sewn and stapled anastomoses may be the result of insufficient mucosal apposition by stapling. Polglase and coworkers ${ }^{29}$ demonstrated rapid epithelialization of sutured colon anastomoses in the dog model, whereas 2 to 4 $\mathrm{mm}$ gaps were present in mucosal approximation in stapled anastomoses, so that the surface healed by second intention with granulation tissue (and fibrosis) formation. In a group of patients with a sutured esophagogastrostomy, the anastomosis was performed with a one-layer continuous suture. In this study the one-layer anastomosis has been shown to be superior to the two-layer procedure because fibrotic strictures are less prevalent. ${ }^{12}$ Both a continuous and an interrupted monolayer esophagogastric anastomosis have been equally effective, although the continuous technique is time saving, cheaper, and easier to perform. ${ }^{13}$

In our study, endoscopic bougie dilation was successful in treating dysphagia in 89 of $114(78 \%)$ patients (see Fig 3). The procedure was usually 
performed on an outpatient basis. Dilation of esophagogastrostomy strictures has also been reported in other studies. ${ }^{8,10,11,15-18}$ In several studies, dilation by endoscopic balloon dilation was effective in improving dysphagia. ${ }^{15-18}$. However, in patients with benign esophageal peptic strictures, Cox and associates ${ }^{30}$ found bougie dilation to be more effective in reducing dysphagia than balloon dilation, and, particularly, in maintaining stricture patency. As in other series, ${ }^{8,10}$ patients in our study reported complete relief of dysphagia after a median of three bougie dilation sessions. Pierie and coworkers ${ }^{11}$ reported a similar success rate $(83 \%)$, but after a median of 9.5 treatment sessions. The reason for this disparity is not clear, because no data on dilator diameter at each session were given. Moreover, in that study patients were only occasionally sedated during dilation procedures. We have found that the patients should always be mildly sedated (intravenous midazolam) during dilation of these strictures to achieve optimal bougie diameter. Major complications occurred in two of $519(0.4 \%)$ dilation sessions.

In conclusion, this largest published study of esophagogastric strictures demonstrates that patients with a history of cardiac disease are at an increased risk for the development of anastomotic strictures. Moreover, careful surgical technique is an important factor in preventing these strictures. Endoscopic bougie dilation is a safe and effective treatment of these strictures, best performed with the patient mildly sedated.

We thank Mrs. C. M. Vollebregt-Uiterwijk for her invaluable assistance.

\section{REFERENCES}

1. Bremner RM, DeMeester TR. Surgical treatment of esophageal carcinoma. Gastroenterol Clin North Am 1991;20:74363.

2. Goldminc M, Maddern G, LePrise E, Meunier B, Campion JP, Launois B. Oesophagectomy by a transhiatal approach or thoracotomy: a prospective randomized trial. Br J Surg 1993;80:367-80.

3. Fok $M$, Wong J. Oesophageal cancer treatment: curative modalities. Eur J Gastroenterol Hepatol 1994;6:676-83.

4. McManus KG, Ritchie AJ, McGuigan J, Stevenson HM, Gibbons JRP. Sutures, staplers, leaks and strictures: a review of anastomoses in oesophageal resection at Royal Victoria Hospital, Belfast 1977-1986. Eur J Cardiothorac Surg 1990; 4:97-100.

5. Tilanus HW, Langenhorst BLAM. Morbidity and mortality after oesophageal resection without thoracotomy. Gullet 1991;1:122-5.

6. Griffin SM, Woods SDS, Chan A, Chung SCS, Li AKC. Early and late surgical complications of subtotal oesophagectomy for squamous carcinoma of the oesophagus. J R Coll Surg Edinb 1991;36:170-3.

7. Fok M, Ah-Chong AK, Chenh SWK, Wong J. Comparison of a single layer continuous hand-sewn method and circular stapling in 580 oesophageal anastomoses. Br J Surg 1991;78: $342-5$.

8. Wang LS, Huang MH, Huang BS, Chien KY. Gastric substitution for resectable carcinoma of the esophagus: an analysis of 368 cases. Ann Thorac Surg 1992;53:289-94.

9. Lam TCF, Fok M, Cheng SWK, Wong J. Anastomotic complications after esophagectomy for cancer: a comparison of neck and chest anastomoses. J Thorac Cardiovasc Surg 1992;104:395-400.

10. Dewar L, Gelfand G, Finley RJ, Evans K, Inculet R, Nelems B. Factors affecting cervical anastomotic leak and stricture formation following esophagogastrectomy and gastric tube interposition. Am J Surg 1992;163:484-9.

11. Pierie JPEN, de Graaf PW, Poen $H$, van der Tweel I, Obertop $\mathrm{H}$. Incidence and management of benign anastomotic stricture after cervical oesophagogastrostomy. Br J Surg 1993;80:471-4.

12. Zieren HU, Müller JM, Pichlmaier H. Prospective randomized study of one- or two-layer anastomosis following oesophageal resection and cervical oesophagogastrostomy. Br J Surg 1993;80:608-11.

13. Bardini R, Bonavina L, Asolati M, Ruol A, Castoro C, Tiso E. Single-layered cervical esophageal anastomoses: a prospective study of two suturing techniques. Ann Thorac Surg 1994;58:1087-90

14. Bardini R, Asolati M, Ruol A, Bonavina L, Baseggio S, Peracchia A. Anastomosis. World J Surg 1994;18:373-8.

15. Fregonese D, Di Falco G, Di Toma F. Balloon dilatation of anastomotic intestinal stenoses: long-term results. Endoscopy 1990;22:249-53.

16. Tam PKH, Sprogg A, Cudmore RE, Cook RCM, Carty H. Endoscopy-guided balloon dilatation of esophageal strictures and anastomotic strictures after oesophageal replacement in children. J Pediatr Surg 1991;26:1101-3.

17. Inagake M, Yamane $\mathrm{T}$, Kitao $\mathrm{Y}$, et al. Balloon dilatation for anastomotic strictures after upper gastro-intestinal surgery. World J Surg 1992;16:541-4.

18. Chen PC. Endoscopic balloon dilatation of esophegeal strictures following surgical anastomoses, endoscopic variceal sclerotherapy, and corrosive ingestion. Gastrointest Endosc 1992;38:586-9.

19. Savary M, Haury JA, Monnier P. Les troubles de la déglution: diagnostic et traitement. Rev Med Suisse Romande 1986;106:313-41.

20. Kaplan EL, Meier P. Nonparametric estimation from incomplete observations. J Am Stat Asșoc 1958;53:457-81.

21. Cox DR. Regression models and life-tables. J R Stat Rec (B) 1972;34:187-220.

22. Orringer MB, Marshall B, Stirling MC. Transhiatal esophagectomy for benign and malignant disease. I Thorac Cardiovasc Surg 1993;105:265-77.

23. Wong J, Cheung H, Lui R, Fan YW, Smith A, Siu KF. Esophagogastric anastomosis performed with a stapler: the occurrence of leakage and stricture. Surgery 1987;101:408-15.

24. Agossou-Voyème AK, Hureau J, Germain M. Arterial vascularization of the operated stomach: highly selective vagotomy, anterior lesser curve seromyotomy, esophageal replace- 
ment by transposed stomach after esophagectomy or circular pharyngolaryngectomy. Surg Radiol Anat 1990;12:247-57.

25. Ueo H, Abe R, Takeuchi H, Arinaga S, Akiyoshi T. A reliable operative procedure for preparing a sufficiently nourished gastric tube for esophageal reconstruction. Am J Surg 1993;165:273-6.

26. Aiko S, Ando N, Shinozawa $Y$, et al. Increased chemiluminescence and ulcer development in the low blood flow state of the gastric tube for esophageal replacement. J Clin Gastroenterol 1993;17(Suppl 1):S161-6.

27. Patil PK, Patel SG, Mistry RC, Deshpande RK, Desai PB. Cancer of the esophagus: esophagogastric anastomotic leak-a retrospective study of predisposing factors. J Surg Oncol 1992;49:163-7.

28. Lee Y, Fujita H, Yamana H, Kakegawa T. Factors affecting leakage following esophageal anastomosis. Surg Today 1994; 24:24-9.

29. Polglase AL, Hughes ESR, McDermott FT, Pihl E, Burke FR. A comparison of end-to-end staple and suture colorectal anastomosis in the dog. Surg Gynecol Obstet 1981; 152:792-6.

30. Cox JGC, Winter RK, Maslin SC, et al. Balloon or bougie dilatation of benign oesophageal stricture? An interim report of a randomised controlled trial. Gut 1988;29:1741-7.

\section{Commentary}

The efficacy and safety of transhiatal esophagectomy is now widely established, and this report by Honkoop and associates corroborates an impressive $2 \%$ hospital mortality in 281 patients undergoing the procedure. The object of esophageal resection and reconstruction, however, is restoration of comfortable swallowing, and these authors report a disturbing and unacceptable $42 \%$ incidence of benign stricture at the cervical esophagogastric anastomosis (114 of the 269 patients surviving the operation). This report, however, incorrectly states that every patient with any degree of dysphagia after a ceivical esophagogastric anastomosis has an anastomotic stricture, and this misconception skews the data presented and the authors' management of these patients.

It has long been appreciated by esophageal surgeons that the prevalence of postoperative dysphagia after any type of esophageal anastomosis increases with the height of the anastomosis. Not infrequently with a cervical esophagogastric anastomosis within 4 to $5 \mathrm{~cm}$ of the upper esophageal sphincter, patients initially experience a "lump in the throat" sensation with swallowing as the bolus of food negotiates the transition from peristaltic esophagus to the less motile gastric conduit. As postoperative anastomotic edema and denervation injury to the cervical esophagus resolve and pharyngoesophageal swallowing becomes more effective in propelling food distally, early postoperative dysphagia may resolve spontaneously. In our patients who acknowledge having any degree of cervical dysphagia at the time of their first postoperative visit at approximately 1 month, passage of $40 \mathrm{~F}, 46 \mathrm{~F}$, and $50 \mathrm{~F}$ tapered Maloney dilators without sedation, anesthesia, or endoscopy is effective treatment. Most often, no resistance, bleeding, or pain is encountered as these dilators are passed for the "functional" dysphagia, which is not the result of an anastomotic stricture.

Similarly, patients with a cervical esophagogastric anas- tomosis who leave the hospital with no dysphagia because they have been limited to a mechanical soft diet may experience cervical dysphagia in the ensuing weeks as they experiment with foods of more normal consistency. Reiative narrowing of the lumen at the transition of cervical esophagus to stomach may be demonstrated with a barium swallow or even an endoscope, but this does not represent a true fibrotic anastomotic stricture. Such diagnostic studies are unwarranted, inasmuch as simple passage of dilators alleviates the problem in the great majority. Only in the rare patient with a cervical esophagogastric anastomosis is it necessary to resort to endoscopic dilation, even in those in whom a fibrotic stricture develops and necessitates some degree of force in passage of the dilators. Our patients are told to return for a dilation if troublesome dysphagia recurs. If the need for dilation becomes more frequent than every 2 weeks, the patient and a family member are taught to pass a $46 \mathrm{~F}$ or larger dilator over several sessions, and home self-dilations are initiated. The patient is instructed to pass the dilator daily for 1 week, then every other day for 1 week, then every third day, and so forth until he or she establishes the longest tolerable interval between dilations. Frequent dilations stretch collagen at the site of the stricture, and a patent anastomosis, maintained with between one to three self-dilations per year, is generally achieved.

Endoscopic dilations in the management of dysphagia after a cervical esophagogastric anastomosis are neither cost effective nor necessary in the vast majority of these patients. Postdilation overnight observations and mortality from perforation, described in a small number of this reported series, are virtually unheard of after passage of mercury-filled tapered Maloney bougies.

At least as important in the management of dysphagia after a cervical esophagogastric anastomosis is prevention of anlastomotic stenosis. In my experience with more than 900 transhiatal esophagectomies and cervical esophagogastric anastomoses, one third of patients with a cervical esophagogastric anastomotic leak will have a subsequent stricture; in this report, the incidence was $57 \%$. Now that the method for safe transhiatal resection of the esophagus is widely established, the challenge before us is to decrease the incidence of cervical esophagogastric anastomosis to as near $0 \%$ as possible. How? The mobilized stomach is relatively ischemic at the fundic end, being dependent on submucosal collaterals fed by the right gastroepiploic and right gastric arteries (the latter of which should be preserved when possible). The authors' reported technique of creating a $3 \mathrm{~cm}$ gastric tube for esophageal replacement only further reduces the available collateral flow from the lesser curvature aspect of the stomach. As much stomach as possible, consistent with a reasonable cancer operation, should be preserved to maximize gastric viability. Other than the aesthetic appeal of creating an esophageal replacement that looks more like an esophagus, there is no advantage to "tubing" the stomach, which sacrifices both gastric volume and microcirculation. A further insult to the blood supply of the mobilized stomach occurs when traction sutures are used to draw the stomach through the posterior mediastinum or suspension sutures are placed to anchor the stomach to the prevertebral fascia in the neck. Both of these latter 


\section{Honkoop et al.}

steps, which I initially advocated, are now being assiduously avoided to minimize further trauma to an already traumatized mobilized stomach, the relatively ischemic tip of which is anastomosed to the cervical esophagus.

Finally, there are now numerous reports of an unacceptable stricture rate in stapled cervical esophagogastric anastomoses (nearly a $48 \%$ incidence in this series). A meticulously performed manual cervical esophagogastric anastomosis is the current standard, and a stapled anastomosis should be avoided. It is difficult to accept the authors' contention that preoperative cardiac disease is a risk factor for cervical esophagogastric
The Journal of Thoracic and Cardiovascular Surgery June 1996

anastomosis stricture. Neither the patient's age nor cardiac status, in my experience, is nearly so important as operative technique in determining the likelihood of anastomotic leak or stricture. Passage of a $46 \mathrm{~F}$ or larger tapered esophageal dilator-without endoscopy or sedation-for dysphagia in a patient with a cervical esophagogastric anastomosis generally results in comfortable swallowing and is not necessarily indicative of a stricture.

Mark B. Oringer, $M D$ Ann Arbor, Mich.

12/1/70795

\section{Bound volumes available to subscribers}

Bound volumes of The Journal of Thoracic and Cardiovascular Surgery are available to subscribers (only) for the 1996 issues from the Publisher, at a cost of $\$ 100.50$ for domestic, $\$ 128.94$ for Canadian, and $\$ 120.50$ for international subscribers for Vol. 111 (January-June) and Vol. 112 (July-December). Shipping charges are included. Each bound volume contains a subject and author index and all advertising is removed. Copies are shipped within 60 days after publication of the last issue of the volume. The binding is durable buckram with the Journal name, volume number, and year stamped in gold on the spine. Payment must accompany all orders. Contact Mosby-Year Book, Inc., Subscription Services, 11830 Westline Industrial Drive, St. Louis, Missouri 63146-3318, USA; phone 800-453-4351 or 314-453-4351.

Subscriptions must be in force to qualify. Bound volumes are not available in place of a regular Journal subscription. 